\title{
Nosocomial outbreak of hepatitis B virus infection in a paediatric haematology and oncology unit in South Africa: Epidemiological investigation and measures to prevent further transmission
}

\section{Names of authors:}

Ané Büchner*(1), Nicolette M. Du Plessis*(2), David T. Reynders (1), Fareed E.

Omar (1), Simnikiwe H. Mayaphi (3), Ahmad F. Haeri Mazanderani (3), Theunis Avenant (2)

\section{Authors' degrees}

Ané Büchner:

MBChB, DCH, FCPaed(SA), MMed(Paed), Cert.

Medical Oncology (Paed)

Nicolette Marié Du Plessis:

MBChB, DipAllerg(SA), FCPaed(SA),

MMed(Paed), Dip HIV Man(SA), Cert ID Paed(SA)

David T Reynders:

MBChB, FCPaed(SA), MRCPCH, Cert. Medical

Oncology (Paed)

Fareed Ebrahim Omar: $\quad$ MBChB, FCPaed(SA), Cert. Medical Oncology

(Paed)

Simnikiwe Horatious Mayaphi: MBChB, FCPath (SA) Viro

Ahmad Haeri-Mazanderani: $\quad$ MBChB, Dip HIV Man(SA)

Theunis Avenant: $\quad$ MBChB, MMed(Paed), FCPaed(SA)

\section{Name of institution/department:}

(1) Paediatric Haematology and Oncology Unit, Steve Biko Academic Hospital, University of Pretoria

(2) Paediatric Infectious Diseases Unit, Kalafong Provincial Tertiary Hospital, University of Pretoria

(3) Department of Medical Virology, University of Pretoria and National Health Laboratory Service, Tshwane Academic Division 
*A.B. and N.d.P contributed equally to this manuscript

Corresponding author:

Ané Büchner

Paediatric Oncology Unit

Department of Paediatrics

Steve Biko Academic Hospital

Oncology Complex level 4

Telephone: 0822147721

Email: ane.buchner@up.ac.za

Abbreviated and running title:

Nosocomial outbreak of HBV infection

Abbreviations key:

\begin{tabular}{|l|l|}
\hline HBV & Hepatitis B virus \\
\hline HBsAg & Hepatitis B surface antigen \\
\hline Anti-HBs & Hepatitis B surface antibodies \\
\hline Anti-HBc & Hepatitis B core antibodies \\
\hline HIV & Human immunodeficiency virus \\
\hline SANBS & South African National Blood Service \\
\hline NAT & Nucleic acid Amplification Technology \\
\hline
\end{tabular}




\section{ABSTRACT}

\section{Background}

Hospital-acquired hepatitis B virus (HBV) infection has been well described and continues to occur worldwide. Recent nosocomial outbreaks have been linked to unsafe injection practices, use of multi-dose vials, and poor staff compliance with standard precautions. This report describes a nosocomial outbreak that occurred in a paediatric haematology and oncology unit of a large academic hospital, the epidemiological investigation of the outbreak, and preventive measures implemented to limit further in-hospital transmission.

\section{Methods}

Outbreak investigation including contact tracing and HBV screening were initially carried out on all patients seen by the unit during the same period as the first three cases. Routine screening for the entire patient population of the unit was initiated in February 2013 when it was realised that numerous patients may have been exposed.

\section{Results}

Forty-nine cases of HBV infection were confirmed in 408 patients tested between July 2011 and October 2013. Phylogenetic analysis of the HBV preC/C gene nucleotide sequences revealed that all tested outbreak strains clustered together. Most $(67 \%)$ patients were HBeAg positive. The cause of transmission could not be

established. Preventive measures targeted three proposed routes. HBV screening and vaccination protocols were started in the unit.

\section{Conclusions}

The high number of HBeAg positive patients, together with suspected lapses in infection prevention and control measures, are believed to have played a major role 
in the transmission. Measures implemented to prevent further in-hospital transmission were successful. On-going HBV screening and vaccination programmes in paediatric haematology and oncology units should become standard of care.

\section{Keywords:}

Outbreak, Oncology, Hepatitis B

\section{Introduction}

Hospital-acquired hepatitis B virus (HBV) infection has been well described and continues to occur worldwide [1-4]. Nosocomial HBV infection has traditionally been associated with the transfusion of contaminated blood and blood products. From the mid-1980s donor-screening programmes and testing of all donated blood has led to a dramatic decrease in transfusion-associated HBV infections [1-2]. Nosocomial outbreaks have been linked to unsafe injection practices, use of multi-dose vials, and poor staff compliance with standard precautions including hand washing $[1,2,5]$.

Multiple HBV outbreaks have been reported in paediatric oncology inpatient settings $[2,6-8]$. The increased risk of HBV infection in these patients may be attributed to a multitude of factors, including immunodeficiency caused by the underlying malignancy and cytostatic chemotherapy [2,9]. Long-term admissions, because of prolonged treatment plans and travel restrictions, as well as poor HBV immunity, are also found in South Africa [6,10]. Although the Expanded Programme on Immunisation in South Africa (EPI-SA) schedules HBV vaccinations during infancy, 
recent data suggest that children in haematology and oncology units have no or very low anti-HBV antibody titres [10].

This article describes a nosocomial outbreak that occurred in a paediatric haematology and oncology unit of a large academic hospital, the epidemiological investigation of this outbreak, and preventive measures implemented to limit further in-hospital transmission. These measures include strict enforcement of standard precautions of infection control and the implementation of an immunisation programme for all patients admitted into the unit.

\section{Materials and methods}

\section{Patients}

The study included patients treated in the paediatric haematology and oncology unit of a large academic hospital in South Africa. The unit has a total of 30 inpatient beds and 10 beds for daytime admissions. Approximately 120 new patients are managed in the unit every year. Most of the patients are repeatedly admitted to the unit during their treatment. On initial assessment all patients are screened for HBV immunity and infection with hepatitis B surface antigen (HBsAg), hepatitis B surface antibodies (anti-HBs), and hepatitis B core antibodies (anti-HBc). All patients entering the unit are routinely tested for human immunodeficiency virus (HIV) infection after consent has been obtained. Routine HBV re-immunisation of seronegative patients was not done before this outbreak.

The first three cases of HBV infection that initiated the outbreak investigation were diagnosed over a 50-day period (March to April 2012). They were asymptomatic and 
presented with deranged liver enzymes on routine blood monitoring. All these patients had tested negative for $\mathrm{HBsAg}$ and anti-HBc on first admission to the unit.

Outbreak investigation including contact tracing and HBV screening were initially carried out on all patients seen in the outpatient clinic and those admitted to the unit during the same period as the infected patients. During this first screening period (May 2012 - January 2013) 18 patients tested positive for HBsAg. Routine screening for the unit's entire patient population (approximately 400 patients) was initiated in February 2013 when it was realised that the probable HBV transmission events were multi-focal and numerous patients may have been exposed. Possible transmission events that occurred 12 months prior to the first diagnosed HBV cases were also investigated.

This article was approved by the Faculty of Health Sciences Research Ethics Committee (Protocol 259/2014). Written permission to publish the data was obtained from the hospital management.

\section{Case definition}

An outbreak-associated case of HBV infection was defined as a patient seen in the unit, who became HBsAg positive and/or anti-HBc positive in the period July 2011 to October 2013. Symptomatic HBV infection was defined as a patient with one or more of the following symptoms at the time of HBV diagnosis: jaundice, nausea and vomiting, and right upper quadrant abdominal pain. 


\section{Serological testing}

All HBV serological testing was performed using Architect Immunoassays (Abbott Diagnostics, Sligo, Republic of Ireland). HBV viral load testing was performed using the Cobas AmpliPrep/Cobas TaqMan HBV Test v2.0 (Roche Molecular Systems, Inc., Branchburg, NJ).

\section{Phylogenetic analysis}

Viral nucleic acid was extracted from $1000 \mu$ l of plasma using the MagNa Pure LC Total Nucleic Acid Isolation kit in the MagNa Pure LC instrument (Roche Diagnostics, Mannheim, Germany) according to the manufacturer's instructions. HBV preC/C primers were used for nested HBV-PCR as previously described [11]. Sequencing was performed at Inqaba Biotechnical company using published preC/C primers and method [12].

\section{Epidemiological investigation}

All the medical information of the patients involved in the outbreak was gathered, including primary diagnosis, HIV status, outcome, as well as the serological markers of $\mathrm{HBV}$ infection.

\section{Preventive measures}

In response to the outbreak, all personnel working in the unit were re-educated about HBV transmission routes. The use of standard precautions including routine handwashing, usage of gloves, application of alcohol-containing hand spray, and appropriate waste disposal were reinforced. The practice of using multi-dose vials was abandoned. 
Patients receiving treatment and the long-term follow-up patients who did not have sufficient immunity against HBV were given a hepatitis B vaccine booster dose, Heberbiovac HB (Centre for Genetic Engineering and Biotechnology, Havana, Cuba). We regard anti-HBs levels $>100 \mathrm{mlU} / \mathrm{mL}$ as protective in our unit. This is based on previous reports which suggested that low immunity with anti-HBs levels between 10 and $100 \mathrm{mlU} / \mathrm{mL}$, especially in immune compromised individuals, was not regarded as sufficiently protective [13-15]. Boosting of low levels of HBV immunity $(10-100 \mathrm{mlU} / \mathrm{mL})$ then became standard of care in patients. A full vaccination schedule $(0,1,2,6$ months) is now given to patients with anti-HBs levels of $<10 \mathrm{mlU} / \mathrm{mL}$, and a single booster vaccine to patients with anti-HBs levels of 10 $100 \mathrm{mIU} / \mathrm{mL}$.

\section{Results}

\section{Patient characteristics}

During the outbreak investigation and the subsequent routine HBV screening in the unit, 408 patients have been tested for HBV. Forty-nine cases of HBV infection were confirmed from July 2011 to October 2013. Table I shows the timeline of events and the actions taken at each time point. Patient characteristics are summarized in Table II. There were 30 boys and 19 girls with confirmed HBV infection, and the median age of the group was 10.8 years (range 2.0 to 20.5 years). Most of the patients $(67.3 \%)$ were patients diagnosed with haematological malignancies, predominantly acute lymphoblastic leukaemia (19 of the 49 patients). Serum bilirubin and alanine transferase (ALT) levels were raised in seven asymptomatic infected patients, with serum bilirubin levels up to $35 \mu \mathrm{mol} / \mathrm{L}$ and serum ALT levels ranging from 46 to 1131 $\mathrm{U} / \mathrm{L}$. However, these abnormal results were not regarded as a reliable indicator of 
Table I. Timeline of events and actions taken at each time point

\begin{tabular}{|l|l|l|}
\hline Time points & New finding & Measures taken \\
\hline July 2011 & Possible introduction of infection to Unit & Not recognised \\
\hline March/April 2012 & $\begin{array}{l}\text { First three patients noted with } \\
\text { asymptomatic liver disease }\end{array}$ & $\begin{array}{l}\text { Screening of possible contacts } \\
\text { initiated (May 2012 - January 2013) }\end{array}$ \\
\hline February 2013 & $\begin{array}{l}\text { Possibility of multiple transmission } \\
\text { events (21 confirmed cases) }\end{array}$ & $\begin{array}{l}\text { Routine screening of all patients in } \\
\text { the Unit. } \\
\text { Intensification of preventive } \\
\text { measures. } \\
\text { Routine re-immunisation initiated. }\end{array}$ \\
\hline October 2013 & $\begin{array}{l}\text { One patient diagnosed with acute HBV } \\
\text { after negative screening in July 2013 }\end{array}$ & $\begin{array}{l}\text { Unclear transmission event in the } \\
\text { Unit. No new measures taken. }\end{array}$ \\
\hline
\end{tabular}

Table II. Patient characteristics of the confirmed HBV cases

\begin{tabular}{|ll|}
\hline Patients (n=49) & \\
\hline Age (years) (range) & $10.8(2.0-20.5)$ \\
Male:Female ratio & $1: 0.63$ \\
Haematological malignancies & $33(67.3 \%)$ \\
Acute lymphoblastic leukemia (ALL) & $19(38.8 \%)$ \\
Acute myeloid leukemia (AML) & $5(10.2 \%)$ \\
Non-Hodgkins lymphoma (NHL) & $5(10.2 \%)$ \\
Hodgkins disease (HD) & $3(6.1 \%)$ \\
Chronic myeloid leukemia (CML) & $1(2 \%)$ \\
Solid tumours & $13(26.5 \%)$ \\
Benign haematological conditions & $3(6.1 \%)$ \\
HIV infection & $4(8.1 \%)$ \\
Asymptomatic HBV infection & $39(79.6 \%)$ \\
Symptomatic HBV infection & $10(20.4 \%)$ \\
(jaundice, hepatomegaly, nausea) & \\
\hline
\end{tabular}

HBV-related liver damage in a setting where administration of cytotoxic chemotherapy often leads to similar biochemical abnormalities [2]. Forty of the fortynine (82\%) HBV positive patients were undergoing chemotherapy. 


\section{Serological markers}

Initial HBV screening data were not available for 10 of the 49 infected patients. Only four patients had evidence of sufficient immunity on first contact to the unit, with antiHBs levels $>100 \mathrm{mIU} / \mathrm{mL}$. (Serological profiles are summarised in Table III.) Thirtythree $(67 \%)$ patients were HBeAg positive. The HBV viral load, available for 31 patients had a mean of $68,739,713 \mathrm{IU} / \mathrm{mL}$, with a range of $<50 \mathrm{IU} / \mathrm{mL}$ to $\geq 170,000,000 \mathrm{IU} / \mathrm{mL}$.

Table III. Serological profiles of the 49 children included in the outbreak, at time of HBV diagnosis

\begin{tabular}{|c|c|c|c|c|c|c|}
\hline HBsAg & Anti-HBs & Anti-HBc & $\begin{array}{c}\text { Anti-HBc } \\
\text { IgM }\end{array}$ & $\mathrm{HBeAg}$ & Anti-HBe & $\begin{array}{c}\text { Number of } \\
\text { patients }\end{array}$ \\
\hline+ & neg & + & + & + & neg & 12 \\
\hline+ & neg & neg & neg & + & neg & 11 \\
\hline neg & + & + & neg & neg & neg & 10 \\
\hline+ & neg & + & neg & + & neg & 6 \\
\hline+ & + & neg & neg & neg & neg & 3 \\
\hline+ & + & + & + & + & neg & 3 \\
\hline+ & neg & + & + & neg & + & 1 \\
\hline+ & + & neg & neg & + & neg & 1 \\
\hline+ & neg & + & neg & neg & + & 1 \\
\hline+ & neg & neg & neg & neg & neg & 1 \\
\hline
\end{tabular}

\section{Phylogenetic analysis}

Phylogenetic analysis was done on eight samples from seven patients. Analysis of the HBV preC/C gene nucleotide sequences revealed that all the outbreak strains clustered together (99\% bootstrap value) and all belonged to genotype E (Figure 1). 


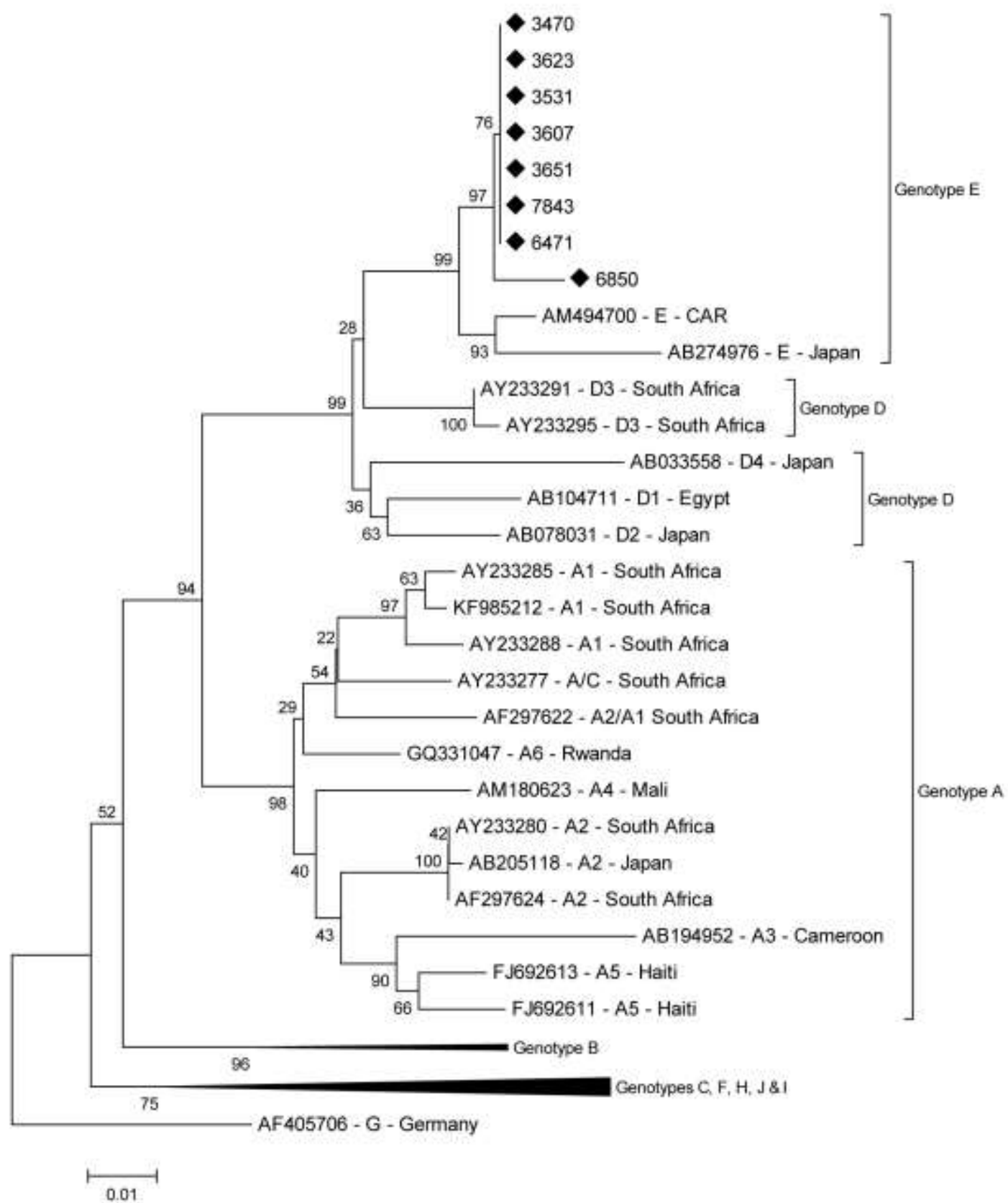

Figure 1

Neighbour joining phylogenetic tree of precore/core gene sequences of HBV, rooted with genotype $\mathrm{G}$ strain. Outbreak samples are labelled with 


\section{Epidemiological investigation}

All medical personnel involved in patient care in the unit were tested for HBsAg and they were advised to seek medical attention and were re-immunised if needed. We were unfortunately unable to access information on the screening of health care workers as a result of patient confidentiality.

All blood products are supplied by the South African National Blood Service (SANBS). From 1984 the SANBS have been actively screening for hepatitis B [16], and since October 2005 Nucleic acid Amplification Technology (NAT) tests have been conducted on every unit of donated blood [17]. No reports of possible windowperiod hepatitis B-containing units were received.

As part of environmental outbreak investigation, HBV PCR testing was done on numerous intravenous access caps (bungs) that were kept together in an antiseptic solution. No evidence of HBV contamination was found; however, HBV DNA could have been degraded or diminished at the time of testing as these caps were kept for a long time in chlorhexidine before testing. The use of multi-dose vials as well as multi-use saline bags (used for flushing intravenous-access catheters) was common practice in the unit during the outbreak period. However, medical staff denied repeated use of the same syringes or needles for different patients.

Although hospital occupancy frequently overlapped, there was no clear pattern of transmission of HBV infection. Patients were not all hospitalised in the same room, but they did share bathrooms and the common dining area. 


\section{Influence of preventive measures}

Measures to prevent further HBV infections were introduced following the outbreak. A HBV re-vaccination programme was introduced for all patients without adequate immunity (anti-HBs $<100 \mathrm{mlU} / \mathrm{mL}$ ). After the introduction of all the preventive measures, only one new case of HBV infection was diagnosed in a patient proven to be HBV-uninfected in July 2013. This patient completed an HBV re-vaccination course in July 2013, but unfortunately tested HBsAg positive in October 2013 with a subsequent detectable viral load. No HBV DNA typing could be done as a result of very low levels of HBV DNA. The patient was HIV infected and on antiretroviral treatment, and was not receiving any inpatient treatment at the time of HBV seroconversion. No new cases of HBV have been recorded from October 2013 until submission of this article (April 2015).

\section{Patient outcomes}

Excluding the patient with acute HBV infection mentioned in the previous paragraph, 20 of the $48(42 \%)$ patients were chronic carriers, $18(38 \%)$ patients cleared HBV infection, two were lost to follow up and eight (17\%) patients died from underlying unrelated medical conditions. Two patients were diagnosed and treated for acute liver failure related to HBV infection. In both these patients the liver function improved, although one of them subsequently died from progression of the primary disease (osteosarcoma).

\section{Discussion}

An unusually high number of HBV infections were recorded in a paediatric haematology and oncology unit during the time period July 2011 to October 2013. 
Preventive measures were implemented to limit further in-hospital transmission of HBV.

There have been multiple reports of HBV outbreaks in paediatric oncology units worldwide [2,6-8]. In our literature search the last reported outbreak in a South African unit occurred over a period of 11 years (1983 to 1994) and included 61 patients [7]. Willers et al reported on paediatric patients that developed active hepatitis B infection during the course of oncology treatment in a South African unit (1998-1999), but did not conduct formal outbreak investigation or phylogenetic studies on samples of these patients [6].

The majority of the patients (67\%) that developed active HBV infection during the described outbreak were patients with haematological malignancies. Possible factors that might predispose this group of patients to develop HBV infection includes: severe immune-suppression secondary to the disease, prolonged hospital admission, repeated venepunctures and an increased need for invasive procedures $[6,9]$. Büchner et al reported on HBV immunity in this group of patients on first admission to the unit, and found a very low rate of sufficient anti-HB levels [10]. Waning of immunity to HBV vaccination is well described in the literature $[18,19]$. In children without chronic disease the immune memory has been shown to be well preserved despite the waning in anti-HBs titers. However, it has been shown even in a group of well children that this waning of HBV immunity places them at risk for breakthrough infection with HBV 10 to 15 years later [18]. Booster dose(s) may be needed in later childhood or early adolescence to provide continuous protection against HBV infection. [19] 
The male:female ratio of patients that acquired HBV was consistent with the patient population treated in the unit, therefore gender did not seem to be a predisposing factor. According to the South African National HIV Survey of 2012, HIV prevalence in children $0-19$ years ranges from $0.7 \%$ to $5.6 \%$ [20]. The higher proportion of HIVinfected patients in this outbreak (8\%) when compared to the national prevalence is in keeping with the known increased risk in HIV-infected patients of developing certain HIV-associated malignancies [21]. The majority (80\%) of the patients described in the outbreak had subclinical HBV infection, which is in accordance with previous reports $[6,8,9]$.

$\mathrm{HBeAg}$ is an indicator of highly replicating hepatitis B virus and its presence indicates a high risk of infectivity. The rate of $\mathrm{HBe}$-antigenaemia in this population $(67 \%)$ is much higher than the $26 \%$ previously reported in African primary school children [22]. This higher rate is likely to be on account of immunosuppression. The high levels of HBV DNA in saliva, previously reported in children with $\mathrm{HBe}$ antigenaemia, support the hypothesis that saliva is a possible vehicle for horizontal transmission of HBV among children [3,23].

Nucleotide sequencing and phylogenetic analysis is currently the gold standard for tracing the origin of large outbreaks [2,4,8]. Eight genotypes of HBV $(A-H)$ are recognised and have a specific geographic distribution [22]. We had access to limited phylogenetic analysis. In contrast to the predominant genotype A found in southern, eastern and central Africa, the phylogenetic analysis done on samples in this outbreak revealed genotype $\mathrm{E}$, which is the most prevalent genotype of western 
and central Africa [22], Outbreak investigations were further limited by a lack of initial serological data of 10/49 patients, one of which could have been the index patient.

Health care workers have been known to transmit HBV infection [24-26]. Testing for and management of HBV infection in health care workers is an important part of outbreak investigation $[5,27]$. We were unable to access information on the screening of health care workers as a result of patient confidentiality. Future screening and vaccination of health care workers should be a transparent process and form part of standard protocol in haematology and oncology units.

Measures implemented to prevent further in-hospital transmission of HBV were successful. Although detailed efficacy data of vaccination strategies on the patients vaccinated in this unit is not yet available, a combination of infection control measures and vaccination has likely contributed to the decrease in active hepatitis B cases. Despite extensive investigations, the exact cause of nosocomial transmission could not be established conclusively. Preventive measures were targeted at the following three proposed routes: lapse in standard precautions between patient contact, use of multi-dose solutions and sharing of personal items (bath towels, toothbrushes and cups) $[2,5,24,28]$. Even though no evidence of contamination was found, the re-use of intravenous access caps (bungs) was stopped. Patients with active HBV infection were isolated as far as possible during admission periods.

Despite being vaccinated as part of the EPI-SA programme, a significant proportion of patients attending the unit do not have sufficient protective antibodies against HBV at first presentation [10]. The lack of adequate or successful immunity response is a 
concern and will need further evaluation on local and programmatic levels. These patients are at risk of acquiring HBV infection in an environment where they may come in contact with highly infectious carriers. All haematology and oncology patients need to be screened for HBV at the first visit and regularly during the course of their treatment and follow up. Preventive measures should be described in a protocol, and include immunisation of all seronegative patients against HBV. Implementation of an effective screening and vaccination programme in the oncology unit should protect these vulnerable patients from contracting HBV.

The use of combined passive-active immunisation should be encouraged, especially in children with haematological malignancies and HIV-infected children where a poor vaccine response is expected $[29,30]$. The use of intravenous specific immune globulin containing high titre of anti-HBs (HBIG) in combination with HBV vaccination in children with malignant diseases has been studied in Poland [29] and India[30]. In both these studies this strategy offered better protection against nosocomial HBV infection than active immunisation alone. The cost implication of offering solely passive prophylaxis during intensive chemotherapy of patients with leukaemia and non-Hodgkin lymphoma led to this protocol being discontinued [29].

Of the HBV-infected children described in this outbreak, $41 \%$ (20/49) were chronic carriers (HBsAg positive for $>6$ months). The rate of chronic carrier state that was found is similar to a published report by Sevinir et al [9]. Patients with chronic HBV infection have an increased risk of developing cirrhosis and hepatocellular carcinoma $[9,22,23]$. The complications of chronic hepatitis could have a detrimental effect on the long-term morbidity of this group of patients, which we are following up closely. 
In conclusion, the high number of $\mathrm{HBeAg}$ positive patients, together with suspected lapses in infection prevention and control measures, are believed to have played a major role in the transmission. Measures implemented to prevent further in-hospital transmission of HBV were successful. On-going HBV screening and vaccination programmes in paediatric haematology and oncology units should become standard of care.

\section{Acknowledgements:}

The authors wish to acknowledge the contribution of all those involved in the study and preparation of the article. Barbara English of the Research Office of the University of Pretoria's Faculty of Health Sciences is thanked for her language editing.

\section{Conflict of interest statement:}

None declared.

\section{Funding sources:}

None.

\section{References}

1. Burns K, Heslin J, Crowley B, Thornton L, Laoi BN, Kelly E, Ward E, Doody B, Hickey MM. Nosocomial outbreak of hepatitis B virus infection involving two hospitals in the Republic of Ireland. J Hosp Infect. 2011:78:279-283. 
2. Dumpis U, Kovalova Ž, Jansons J, Čupane L, Sominskaya I, Michailova M, Karayiannis P, Gardovska D, Viazov S, Ross S, Roggendorf M, Pumpens P. An outbreak of HBV and HCV infection in a paediatric oncology ward: epidemiological investigations and prevention of further spread. J Med Virol. 2003:69:331-338.

3. Kidd-Ljunggren K, Holmberg A, Bläckberg J, Lindqvist B. High levels of hepatitis B virus DNA in body fluids from chronic carriers. J Hosp Infect. 2006:64:352-357.

4. Pourkarim MR, Verbeeck J, Rahman M, Amini-Bavil-Olyaee S, Forier A, Lemey P, Maes P, Van Ranst M. Phylogenetic analysis of hepatitis B virus full-length genomes reveals evidence for a large nosocomial outbreak in Belgium. J Clin Virol. 2009:46:61-68.

5. Michelin A, Henderson DK. Infection Control Guidelines for Prevention of Health Care-Associated Transmission of Hepatitis B and C Viruses. Clin Liver Dis. 2010:14:119-136.

6. Willers E, Webber L, Delport R, Kruger M. Hepatitis B-A Major Threat to Childhood Survivors of Leukaemia/Lymphoma. J Trop Pediatr. 2001:47:220225.

7. Hardie DR, Kannemeyer J, Stannard LM. DNA single strand conformation polymorphism identifies five defined strains of hepatitis B virus (HBV) during an outbreak of HBV infection in an oncology unit. J Mel Virol. 1996:49:49-54.

8. Fisker N, Carlsen NLT, Kolmos HJ, Tønning-Sørensen L, Høst A, Christensen PB. Identifying a hepatitis B outbreak by molecular surveillance: a case study. BMJ. 2006:332:343. 
9. Sevinir B, Meral A, Günay Ü, Özkan T, Özuysal S, Sinirtas M. Increased risk of chronic hepatitis in children with cancer. Med Pediatr Oncol. 2003:40:104110.

10. Büchner A, Omar FE, Vermeulen J, Reynders DT. Investigating hepatitis B immunity in patients presenting to a paediatric haematology and oncology unit in South Africa. S Afr Med J. 2014:104:628-631.

11. Mphahlele MJ, Lukhwareni A, Burnett RJ, Moropeng LM, Ngobeni JM. High risk of occult hepatitis B virus infection in HIV-positive patients from South Africa. J Clin Virol. 2006:35:14-20.

12. Mayaphi SH, Martin DJ, Mphahlele MJ, Blackard JT, Bowyer SM. Variability of the $\mathrm{preC} / \mathrm{C}$ region of hepatitis $\mathrm{B}$ virus genotype A from a South African cohort predominantly infected with HIV. J Med Virol. 2013:85:1883-1892.

13. Hofmann F, Kralj N. Criteria for successful hepatitis B vaccination in adults: results of a case study. Infection. 2009:37:266-269.

14. Tong NK, Beran J, Kee SA, Miguel JL, Sánchez C, Bayas JM, Vilella A, de Juanes JR, Arrazola P, Calbo-Torrecillas F, de Novales EL, Hamtiaux V, Lievens M, Stoffel M. Immunogenicity and safety of an adjuvanted hepatitis B vaccine in pre-hemodialysis and hemodialysis patients. Kidney Int. 2005:68:2298-2303.

15. Han K, Shao X, Zheng H, Wu C, Zhu J, Zheng X, Zhang Y. Revaccination of non- and low- responders after a standard three dose hepatitis B vaccine schedule. Hum Vaccin Immunother. 2012:8:1845-1849.

16. Bird AR, Gibbs BJ. Blood transfusion and hepatitis viruses. S Afr Med J. 1994:84: 570-572. 
17. Vermeulen M, Lelie N, Sykes W, Crookes R, Swanevelder J, Gaggia L, Le Roux M, Kuun E, Gulube S, Reddy R. Impact of individual-donation nucleic acid testing on risk of human immunodeficiency virus, hepatitis B virus, and hepatitis C virus transmission by blood transfusion in South Africa. Transfusion. 2009:49:1115-1125.

18. Lu CY, Chiang BL, Chi WK, Chang MH, Ni YH, Hsu HM, Twu SJ, Su IJ, Huang LM, Lee CY. Waning immunity to plasma-derived hepatitis B vaccine and the need for boosters 15 years after neonatal vaccination. Hepatology. 2004:40:1415-1420.

19. Hammitt LL, Hennessy TW, Fiore AE, Zanis C, Hummel KB, Dunaway E, Bulkow L, McMahon BJ. Hepatitis B immunity in children vaccinated with recombinant hepatitis $B$ vaccine beginning at birth: a follow-up study at 15 years. Vaccine. 2007:25:6958-6964.

20. Simbayi LC, Shisana O, Rehle T, Onoya D, Jooste S, Zungu N, Labadarios D, Zuma K. (2014) South African National HIV Prevalence, Incidence and Behaviour survey, 2012. Cape Town, HSRC Press.

21. Robert J. Biggar MD; Frisch M, Goedert JJ. Risk of cancer in children with AIDS. JAMA. 2000:284:205-209.

22. Kramvis A, Kew MC. Epidemiology of hepatitis B virus in Africa, its genotypes and clinical associations of genotypes. Hepatol Res. 2007:37:S9-S19.

23. Heiberg IL, Hoegh M, Ladelund S, Niesters HGM, Hogh B. Hepatitis B virus DNA in saliva from children with chronic hepatitis B infection: implications for saliva as a potential mode of horizontal transmission. Pediatr Infect Dis J. 2010:29:465-467. 
24. Bell DM, Shapiro CN, Ciesielski CA, Chamberland ME. Preventing bloodborne pathogen transmission from health-care workers to patients. The CDC perspective. Surg Clin North Am. 1995:75:1189-1203.

25. Laurenson IF, Jones DG, Hallam NF, Saunders CJP, Fraser DM, Carman WF. Transmission of hepatitis B virus from a vaccinated healthcare worker. $J$ Hosp Infect. 2007:66:393-394.

26. Harpaz R, Von Seidlein L, Averhoff FM, Tormey MP, Sinha SD, Kotsopoulou K, Lambert SB, Robertson BH, Cherry JD, Shapiro CN. Transmission of hepatitis B virus to multiple patients from a surgeon without evidence of inadequate infection control. N Engl J Med. 1996:334:549-554.

27. Pourkarim MR, Van Ranst M. Guidelines for the detection of a common source of hepatitis B virus infections. Hepatitis Monthly. 2011:11:783-785.

28. Stevens MP, Edmond MB. Health Care-Associated Transmission of Hepatitis B and C in Oncology Care. Clin Liver Dis. 2010:14:69-74.

29. Styczynski J, Wysocki M, Koltan S, Kurylak A. A nine-year experience of immunoprophylaxis against hepatitis B virus infection in children with cancer: results from a single institution in Poland. J Hosp Infect. 2001:48:298-303.

30. Somjee S, Pai S, Parikh P, Banavali S, Kelkar L, Advani S. Passive active prophylaxis against Hepatitis B in children with acute lymphoblastic leukaemia. Leuk Res. 2002:26:989-992. 